\title{
Towards the limits of vibrational circular dichroism spectroscopy: VCD spectra of some alkyl vinylethers
}

\author{
Abstract: Three alkyl vinylethers from our collection of chiral samples were investigated through VCD spectroscopy, \\ in combination with DFT calculations. Despite the simplicity of the compounds, reproducing all the spectra features \\ is an involved task, since the many significantly populated conformers contribute to the total VCD spectrum with bands \\ which often have opposite signatures. Nevertheless, we show that certain bands can be satisfactorily reproduced \\ by calculation and therefore they may be employed for the determination of absolute configuration in these \\ and similar compounds, for which no simple alternative method is available.
}

\section{Francesco Zinna ${ }^{[a]}$ and Gennaro Pescitelli*[a]}

Keywords: VCD, DFT calculations, chiroptical spectroscopy, cryptochirality, absolute configuration, infrared spectroscopy, conformational analysis, Fermi resonance

\section{Introduction}

Determination of absolute configuration with direct methods of non-chromophoric and low molecular weight molecules may reveal particularly challenging. In these cases, electronic circular dichroism (ECD), probably the most widely used chiroptical method to accomplish this task ${ }^{1}$ cannot be of any aid. An obvious case are alkanes ${ }^{2,3}$ and non-conjugated alkenes. ${ }^{4}$ Although several methods exist based on chromophoric derivatives and/or supramolecular approaches, ${ }^{5-7}$ they are based on chemical derivatization and require at least one reactive functional group such as alcohol, amine, carboxylic acid, etc. Quite often, small non-chromophoric molecules show weak or negligible optical rotation, making also the use of this technique challenging. ${ }^{8}$ Moreover, some molecules may be CD silent and display very little or no optical rotation ${ }^{3,9}$ even in the presence of chromophores. ${ }^{10-12}$ This phenomenon is indicated as cryptochirality. When such situations occur, vibrational circular dichroism (VCD) may prove a powerful and relatively easy tool to assess absolute configurations and even support relative configurations determined with other methods. Successful applications of VCD in this field are, among others, ${ }^{13}$ absolute configuration determination of alkanes, ${ }^{14}$ terpenes $^{15,16}$ and glycerophospholipids. ${ }^{17}$

Taking advantage of our relatively vast collection of chiral molecules spanning several classes of organic compounds, we decided to undertake a chiroptical analysis of vinyl ethers. These compounds are used as monomers for the preparation of chiral polyvinylethers, that is polyethylenes appended with chiral ether pendants. ${ }^{18-21}$ To the best of our knowledge, no VCD investigation has been reported so far for this class of compounds.

We chose to analyze three alkyl vinyl ethers 1-3 (Scheme ) in which chirality is brought about by a methyl-ethyl difference at the stereogenic center. In two cases out of three the asymmetric carbon is in position 2 with respect to the oxygen ((S)-2-methyl butyl vinylether 1 and (S)-2-methyl butyl isobutenylether $\mathbf{3}$ ), while in one case it is in position $3((S)-3-$ methyl pentyl vinylether 2$)$.

These three compounds are interesting since they display no significant ECD signal associated with the only accessible electronic transition $\left(\pi \rightarrow \pi^{*}\right.$ at $\left.200 \mathrm{~nm}\right)$ (see Supporting Information), moreover their optical rotation is quite weak $\left([\alpha]_{D}{ }^{25}\right.$ $=+6.65^{\circ},+7.36^{\circ},+1.17^{\circ}$ for compound $\mathbf{1 , 2}$ and 3 respectively), ${ }^{22}$ therefore one cannot rely on these data when trying to assign absolute configurations. Conversely, these compounds display weak but significant VCD spectra in the fingerprint region, which in principle can be satisfactorily employed for their stereochemical characterization. However, as we will show below, VCD calculations are not straightforward, since these compounds - despite their apparent structural simplicity- are endowed with a wealth of conformational possibilities.

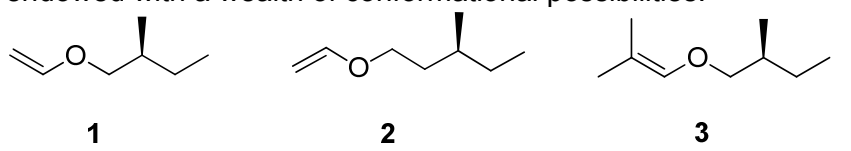

Scheme 1 The three alkyl vinyl ethers investigated in this work.

\section{Materials and Methods}

NMR spectra were measured with a Bruker Avance DRX 400 instrument. VCD spectra were recorded using a Jasco FVS 6000 VCD spectrometer (6000-8000 scans). The instrument performance was checked using $\mathrm{CCl}_{4}$ solutions of (+) and (-)camphor and $(+)$ and (-)-limonene, used as standards, ${ }^{23,24}$ just before measuring the samples. The samples were measured in $\mathrm{CCl}_{4}$ solution $(0.6$ and $0.3 \mathrm{M})$ in a $100 \mu \mathrm{m} \mathrm{KBr}$ cell. At least three different measurements were performed on each sample to check consistency. The spectra displayed in Figure 1 were obtained by subtracting the $\mathrm{CCl}_{4}$ spectrum recorded in the same conditions to the raw spectrum.

(S)-2-methyl butyl vinylether $1:{ }^{1} \mathrm{H}$ NMR $\left(400 \mathrm{MHz}\right.$, chloroform- $d_{3}$, ঠ): 6.50 (dd, $J=7 \mathrm{~Hz} ; 1 \mathrm{H}), 4.80$ (dd, $J=2,14 \mathrm{~Hz} ; 1 \mathrm{H}$ ), 3.98 (dd, $J=2,7 \mathrm{~Hz} ; 1 \mathrm{H}), 3.57$ (dd, $J=6,10 \mathrm{~Hz}, 1 \mathrm{H}) ; 3.48$ (dd, $J=6$, $10 \mathrm{~Hz} ; 1 \mathrm{H}$ ), 1.75 (oct, $J=7 ; 1 \mathrm{H}$ ), 1.50 (sep, $J=7 ; 1 \mathrm{H}$ ), 1.21 (sep, $J=7 ; 1 \mathrm{H}), 0.96$ (d, $J=7 ; 3 \mathrm{H}), 0.93(\mathrm{t}, J=7 ; 3 \mathrm{H})$.

(S)-3-methyl pentyl vinylether 2: ${ }^{1} \mathrm{H}$ NMR $(400 \mathrm{MHz}$, chloroform$\left.d_{3}, \delta\right): 6.49$ (dd, $\left.J=7 \mathrm{~Hz} ; 1 \mathrm{H}\right), 4.19(\mathrm{dd}, J=2,14 \mathrm{~Hz} ; 1 \mathrm{H}), 3.99$ $(\mathrm{dd}, J=2,7 \mathrm{~Hz} ; 1 \mathrm{H}), 3.73(\mathrm{~m} ; 2 \mathrm{H}), 1.73(\mathrm{~m} ; 1 \mathrm{H}), 1.52(\mathrm{~m} ; 1 \mathrm{H})$, $1.39(\mathrm{~m} ; 2 \mathrm{H}), 1.21(\mathrm{~m} ; 1 \mathrm{H}), 0.91(\mathrm{~m} ; 6 \mathrm{H})$.

[a] Dr. F. Zinna, Prof. G. Pescitelli

Dipartimento di Chimica e Chimica Industriale,

Università di Pisa

Via Moruzzi 13, I-56124, Pisa, Italy

E-mail: gennaro.pescitelli@unipi.it

Received: ((will be filled in by the editorial staff)) 

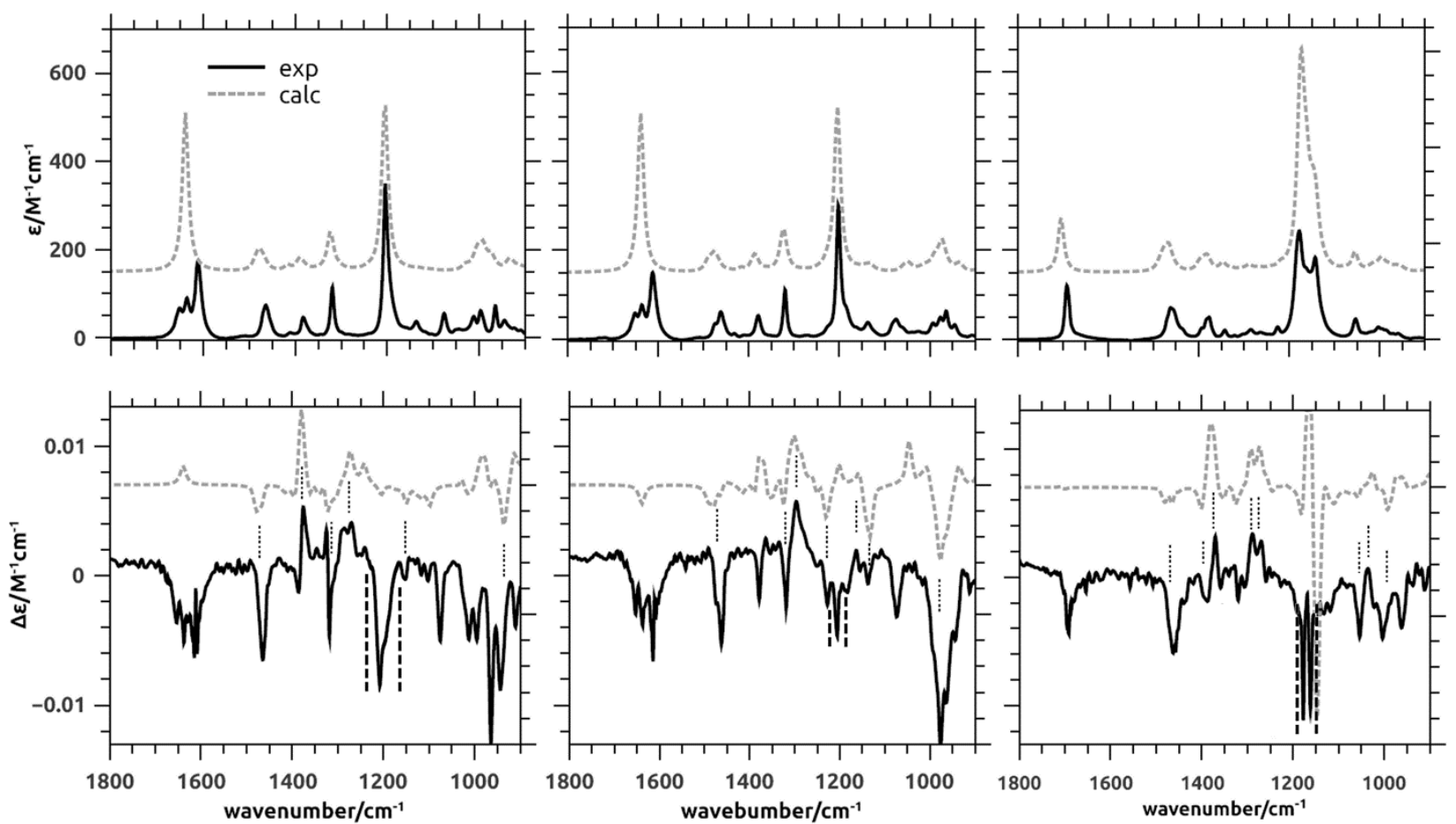

Figure 1: Calculated (dashed line) and experimental (continuous line) IR (top) and VCD (bottom) spectra for compounds 1 (left), 2 (centre) and 3 (right). Calculated spectra are shown with a vertical offset for clarity. The region around $1200 \mathrm{~cm}^{-1}$ enclosed by dashed vertical lines was measured on diluted samples.

(S)-2-methyl butyl isobutenylether 3: ${ }^{1} \mathrm{H} \mathrm{NMR} \quad(400 \mathrm{MHz}$, chloroform- $\left.d_{3}, \delta\right): 5.80(\mathrm{~m} ; 1 \mathrm{H}), 3.54(\mathrm{dd}, J=6,10 \mathrm{~Hz} ; 1 \mathrm{H}), 3.45$ (dd, $J=7,10 \mathrm{~Hz} ; 1 \mathrm{H}), 1.69(\mathrm{~m} ; 1 \mathrm{H}), 1.63(\mathrm{~s} ; 3 \mathrm{H}), 1.56(\mathrm{~s} ; 3 \mathrm{H})$, $1.48(\mathrm{~m} ; 1 \mathrm{H}), 1.18(\mathrm{~m} ; 1 \mathrm{H}), 0.93(\mathrm{~m} ; 6 \mathrm{H})$.

MMFF calculations were run with Spartan'14 (Wavefunction, Inc., Irvine CA, 2014), with standard parameters and convergence criteria. DFT calculations were run with Gaussian'09, ${ }^{25}$ with default grids and convergence criteria. Conformational searches were run with the Monte Carlo algorithm implemented in Spartan'14 using Merck molecular force field (MMFF). All structures thus obtained were optimized with DFT method using B3LYP functional and $6-31 \mathrm{G}+(\mathrm{d}, \mathrm{p})$ or $6-311 \mathrm{G}++(2 \mathrm{p}, 2 \mathrm{~d})$ basis sets in vacuo. Frequency calculations were run at the same level of theory on all conformers with a Boltzmann population $>1 \%$ at $300 \mathrm{~K}$. IR and VCD spectra were obtained as sums of Lorentzian functions with a half-width at half height of $8 \mathrm{~cm}^{-1}$, and a frequency scale factor of 0.98 , and Boltzmann-averaged at $300 \mathrm{~K}$ using internal energies. Average spectra were generated with the software Specdis, v. $1.63 .{ }^{26}$

\section{Results and Discussion}

Compounds 1-3 were synthesized by Salvadori and Lardicci ${ }^{22}$ in 1964 , they also assigned the absolute configuration through chemical correlation and reported their optical rotations. The samples were conserved in sealed glass vial under inert atmosphere in the dark, and their purity was re-checked through ${ }^{1} \mathrm{H}$-NMR shortly before the VCD analysis. Since ${ }^{1} \mathrm{H}-\mathrm{NMR}$ data for these compounds are not available in the literature, we report them in the Materials and Methods section and the spectra in the Supporting Information.

The IR and VCD spectra of compounds 1-3 are reported in Figure 1 (solid lines). We focused our VCD investigation in the $850-2000 \mathrm{~cm}^{-1}$ region. In this region the IR spectra show several prominent features: $=\mathrm{CH}$ out-of-plane deformation $\left(960 \mathrm{~cm}^{-1}\right)$, $=\mathrm{C}-\mathrm{O}-\mathrm{C}$ symmetric $\left(1070 \mathrm{~cm}^{-1}\right)$ and asymmetric stretching (1200 $\left.\mathrm{cm}^{-1}\right),=\mathrm{CH},=\mathrm{CH}_{2},-\mathrm{CH},-\mathrm{CH}_{2}$ and $-\mathrm{CH}_{3}$ in-plane deformation $\left(1320-1460 \mathrm{~cm}^{-1}\right)$ and a rather strong $\mathrm{C}=\mathrm{C}$ stretching $(1610-1650$ $\left.\mathrm{cm}^{-1}\right)$.

The two other bands found experimentally above $1650 \mathrm{~cm}^{-1}$ for compounds $\mathbf{1}$ and $\mathbf{2}$ are often encountered in IR spectra of vinyl ethers and, noteworthy, they are not reproduced by calculations (Figure 1, dotted lines). The older literature ${ }^{27}$ explained them as the $\mathrm{C}=\mathrm{C}$ stretching of less populated rotamers or as overtones of $=\mathrm{CH}_{2}$ out-of-plane deformations, enhanced by Fermi resonance mixing with the strong $\mathrm{C}=\mathrm{C}$ stretching. Our DFT calculations (see below), carried out on all relevant populated conformers, yielded only one band at almost the same frequency for the $\mathrm{C}=\mathrm{C}$ stretching of all low-energy structures, ruling out the contribution by different conformers to this spectral feature. This led us to conclude that the overtone explanation may be the most suitable to rationalize the observed bands above $1650 \mathrm{~cm}^{-1}$. Moreover this explanation is also consistent with the single band observed in this region for isopropenyl ether 3 , since the two $=\mathrm{CH}_{2}$ hydrogen are replaced with two methyl groups and therefore they cannot contribute to overtones at these wavenumbers. It is also noteworthy that in the calculated IR spectra all the intensities match fairly well the experimental ones with the only exception of the band associated with the $\mathrm{C}=\mathrm{C}$ stretching, this can be explained taking into account that the actual intensity of this band is reduced as an additional effect of the Fermi resonance mixing. In compound $\mathbf{3}$, where no mixing occurs, the experimental and calculated intensities of this band do not differ 
significantly. The effects of Fermi resonance are also seen in VCD spectra ${ }^{28,29}$ of $\mathbf{1}$ and $\mathbf{2}$, where the rotational strength of the fundamental vibration at $1610 \mathrm{~cm}^{-1}$ is redistributed within the overtone bands at higher frequencies, giving a multiplet of bands with the same sign (negative for both $\mathbf{1}$ and $\mathbf{2}$, Figure 1).

The experimental VCD spectra show several bands in all the investigated region, most of them with a dissymmetry factor $g$ $(\Delta \varepsilon / \varepsilon)$ of the order of $10^{-4}-10^{-5}$, or $10-100 \mathrm{ppm}$. Thus, most bands satisfy Góbi and Magyarfalvi criterion ${ }^{30}$ for the reliability of VCD measurements, that is $\zeta_{2}=R / D=g / 4>10 \mathrm{ppm}$, where $R$ is the rotational strength and $D$ the dipole strength. The use of $g$-factor is a consolidated method to estimate the match between calculated and experimental VCD spectra. ${ }^{31,32}$ Therefore, we tried to reproduce the VCD spectra through DFT calculations. Despite the simplicity of the compounds, this task is involved due to the high number of populated conformers, contributing with opposite signature to the total spectrum (Supporting Information). We screened the different conformers by means of a systematic conformational search run with molecular mechanics (MMFF force field), followed by DFT geometry optimizations at B3LYP/6$31 \mathrm{G}+(\mathrm{d}, \mathrm{p})$ level. Considering only the conformers with at least $1 \%$ Boltzmann population at $300 \mathrm{~K}$, they amount to 12,14 and 21 for 1, 2 and 3, respectively. In this way, these conformers account for at least 99,90 , and $99 \%$ of the overall population, respectively. All the conformers for compound 1 , and the 4 most populated ones for compounds 2 and $\mathbf{3}$, are shown in the Supporting Information. Structural details in terms on relevant dihedral angles are given for the first eight conformers of compound $\mathbf{1}$ in Table 1 . All of them share the expected s-cis conformation around the $=\mathrm{C}-\mathrm{O}$ bond, namely the $\mathrm{O}-\mathrm{C} 1$ ' bond is eclipsed with the $\mathrm{C}=\mathrm{C}$ double bond, and the anti arrangement around the O-C1' dihedral (Scheme 2). This is in fact the preferred conformation of the parent ethyl vinyl ether. ${ }^{33} \mathrm{~A}$ similar situation is found for $\mathbf{2}$, while in compound $\mathbf{3}$ the favored conformation around the $=\mathrm{C}-\mathrm{O}$ bond is s-trans because of the sterical hindrance of the methyl group cis to the oxygen (see Supporting Information).

TABLE 1 Descriptors of dihedral angles and relative energies for the lowest energy conformers of compound $(R)-1$ calculated at B3LYP/6$31 \mathrm{G}+(\mathrm{p}, \mathrm{d})$ level.

\begin{tabular}{cccccc}
\hline$\#$ & $\mathrm{C1}^{-} \mathrm{O}^{\mathrm{a}}$ & ${\mathrm{O}-\mathrm{C} 1^{\prime}}^{\mathrm{a}}$ & $\mathrm{C1}^{\prime}-\mathrm{C} 2^{\prime}{ }^{\mathrm{a}}$ & $\mathrm{C}^{\prime}-\mathrm{C} 3^{\prime}{ }^{\mathrm{a}}$ & Energy $^{\mathrm{b}}$ \\
1 & $\mathrm{c}$ & $\mathrm{a}$ & $\mathrm{g}-$ & $\mathrm{a}$ & 0 \\
2 & $\mathrm{c}$ & $\mathrm{a}$ & $\mathrm{a}$ & $\mathrm{a}$ & +0.047 \\
3 & $\mathrm{c}$ & $\mathrm{a}$ & $\mathrm{g}+$ & $\mathrm{g}+$ & +0.252 \\
4 & $\mathrm{c}$ & $\mathrm{a}$ & $\mathrm{a}$ & $\mathrm{g}+$ & +0.255 \\
5 & $\mathrm{c}$ & $\mathrm{a}$ & $\mathrm{g}+$ & $\mathrm{a}$ & +0.387 \\
6 & $\mathrm{c}$ & $\mathrm{a}$ & $\mathrm{g}-$ & $\mathrm{g}-$ & +0.765 \\
7 & $\mathrm{c}$ & $\mathrm{a}$ & $\mathrm{a}$ & $\mathrm{g}-$ & +0.992 \\
8 & $\mathrm{c}$ & $\mathrm{a}$ & $\mathrm{g}-$ & $\mathrm{g}+$ & +1.251
\end{tabular}

${ }^{a}$ Rotamerism around the bond; see Scheme 2 for atom numbering. Legend: c, s-cis; a, anti; g+, gauche plus; g-, gauche minus.

${ }^{\mathrm{b}}$ Relative internal energy in $\mathrm{kcal} / \mathrm{mol}$.

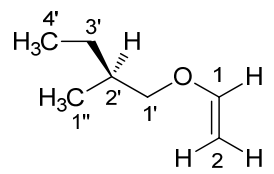

Scheme 2 Most stable conformation of (S)-2-methyl butyl vinylether (1) and atom numbering used in Table 1.

Frequency calculations were carried out on 1-3 at the same B3LYP/6-31G $+(p, d)$ level. The effect of the basis set was investigated carrying out the same calculation for compound 1 with a larger basis $(6-311 \mathrm{G}++(2 \mathrm{p}, 2 \mathrm{~d}))$. The IR and VCD calculated spectra thus obtained were almost coincident with the ones calculated with the smaller basis set (see Supporting Information).

It may be appreciated from Figure 1 that the calculations reproduce fairly well several features of the VCD spectra in all the compounds (see vertical dashed lines). In particular, the following bands offer a useful signature which would allow one to assign the absolute configuration in similar compounds: $=\mathrm{CH}$ outof-plane deformation $\left(960 \mathrm{~cm}^{-1}\right)$; in-plane deformations and skeletal vibrations $\left(1250-1460 \mathrm{~cm}^{-1}\right)$. In particular, the manifold associated with $=\mathrm{CH}_{2}$ In-plane deformations (around $1320 \mathrm{~cm}^{-1}$ ) and the rather strong negative band associated with $\mathrm{CH}_{3}$ deformations (around $1460 \mathrm{~cm}^{-1}$ ), are well reproduced by the calculations in all the cases.

On the other hand, several other bands are not satisfactorily reproduced by the calculations, most likely because of the great variation in the calculated VCD spectra for the individual conformers (see Supporting Information), which introduces a severe source of error in the computations. Among the problematic bands, it is worth noticing that the $=\mathrm{C}-\mathrm{O}-\mathrm{C}$ asymmetric stretching at $1200 \mathrm{~cm}^{-1}$ is not robust according to Góbi and Magyarfalvi criterion, ${ }^{30}$ since the calculated $\zeta_{2}$ (for the most populated conformer) is $\sim 6 \mathrm{ppm}$ for $\mathbf{1}$ and $\sim 3 \mathrm{ppm}$ for 2 and 3, below the $10 \mathrm{ppm}$ threshold. Similarly, for the $\mathrm{C}=\mathrm{C}$ stretching at $1620 \mathrm{~cm}^{-1}$ the calculated $\zeta_{2}$ for the most populated conformer of 1 is $\sim 1 \mathrm{ppm}$, well below the $10 \mathrm{ppm}$ threshold. Therefore this band should be disregarded. Obviously, a correct prediction of the region around $1600 \mathrm{~cm}^{-1}$, including overtones and Fermi resonance, requires an anharmonic computational approach. ${ }^{34}$ Finally it is interesting to note that compounds $\mathbf{1}$ and $\mathbf{2}$ which bear chirality in position 2 and 3 respectively, and share otherwise a similar skeleton and the same configuration, should in principle lead to an odd-even effect such as that observed by Nafie et al. ${ }^{35}$ for chiral alcohols. However, most VCD bands, in either the experimental or calculated spectra, have the same sign for $\mathbf{1}$ and $\mathbf{2}$, demonstrating that in the present case no oddeven effect is evident.

\section{Conclusion}

We have shown that simple chiral alkyl vinyl ethers can be conveniently characterized only through VCD spectroscopy, but not ECD or optical rotation. However, many conformers are significantly populated at room temperature, and each of them gives a different contributions to the total VCD spectrum with bands displaying opposite sign and variable intensity. Thus, special care should be taken in interpreting calculation results and comparing them with the experiment. Nevertheless some bands, and most notably the signals associated with the deformations in the $1300-1460 \mathrm{~cm}^{-1}$ region, could offer a useful fingerprint to solve absolute configuration problems for this class of compounds and similar ones.

\section{Acknowledgements}

Prof. Lorenzo Di Bari is gratefully thanked for useful discussions.

\section{Supporting information}

Additional supporting information may be found in the online version of this article at the publisher's website. It contains: VCD spectra calculated for 1 with different basis sets; UV and ECD spectra of 1-3; VCD spectra calculated for different conformers of 1-3; structures and relative energies of low-energy conformers of 1-3; ${ }^{1} \mathrm{H}$ NMR spectra of 1-3.

\section{REFERENCES}

1. Berova N, Di Bari L, Pescitelli G. Application of electronic circular dichroism in configurational and conformational analysis of organic compounds. Chem Soc Rev 2007;36:914-931. 
2. Kuwahara S, Obata K, Fujita T, Miura N, Nakahashi A, Monde K, Harada N. (R) (+) [VCD (-) 984] 4 Ethyl 4 methyloctane: A Cryptochiral Hydrocarbon with a Quaternary Chiral Center.(2) Vibrational CD Spectra of Both Enantiomers and Absolute Configurational Assignment. Eur. J. Org. Chem. 2010;2010:63856392.

3. Wynberg H, Hekkert G, Houbiers J, Bosch H. The Optical Activity of Butylethylhexylpropylmethane1. J. Am. Chem. Soc. 1965;87:2635-2639.

4. Longhi G, Abbate S, Gangemi R, Giorgio E, Rosini C. Fenchone, camphor, 2-methylenefenchone and 2-methylenecamphor: A vibrational circular dichroism study. J. Phys. Chem. A 2006;110:4958-4968.

5. Berova N, Pescitelli G, Petrovic AG, Proni G. Probing molecular chirality by $C D$-sensitive dimeric metalloporphyrin hosts. Chem. Commun. 2009:5958-5980.

6. Harada N, Nakanishi K, Berova N. Electronic CD Exciton Chirality Method: Principles and Applications. In: Berova N, Polavarapu PL, Nakanishi K, Woody RW, editors. Comprehensive Chiroptical Spectroscopy. Hoboken (NJ): John Wiley \& Sons, Inc.; 2012. p 115-166.

7. Superchi S, Rosini C, Mazzeo G, Giorgio E. Determination of molecular absolute configuration: guidelines for selecting a suitable chiroptical approach. In: Berova N, Polavarapu PL, Nakanishi K, Woody RW, editors. Comprehensive Chiroptical Spectroscopy. Hoboken (NJ): John Wiley \& Sons, Inc.; 2012. p 421-447.

8. Stephens PJ, McCann DM, Cheeseman JR, Frisch MJ. Determination of absolute configurations of chiral molecules using ab initio time-dependent Density Functional Theory calculations of optical rotation: How reliable are absolute configurations obtained for molecules with small rotations? Chirality 2005;17:E52-E64.

9. Kawasaki T, Tanaka H, Tsutsumi T, Kasahara T, Sato I, Soai K. Chiral discrimination of cryptochiral saturated quaternary and tertiary hydrocarbons by asymmetric autocatalysis. J. Am. Chem. Soc. 2006;128:6032-6033.

10. Kawasaki T, Hohberger C, Araki Y, Hatase K, Beckerle K, Okuda $\mathrm{J}$, Soai K. Discrimination of cryptochirality in chiral isotactic polystyrene by asymmetric autocatalysis. Chem. Commun. 2009:5621-5623.

11. Peerlings HW, Trimbach D. Chiral dendrimers with backfolding wedges. Chem. Commun. 1998:497-498.

12. Amako T, Nakabayashi K, Suzuki N, Guo S, Rahim NAA, Harada $\mathrm{T}$, Fujiki M, Imai $\mathrm{Y}$. Pyrene magic: chiroptical enciphering and deciphering 1, 3-dioxolane bearing two wirepullings to drive two remote pyrenes. Chem. Commun. 2015;51:8237-8240.

13. Freedman TB, Cao $X$, Dukor RK, Nafie LA. Absolute configuration determination of chiral molecules in the solution state using vibrational circular dichroism. Chirality 2003;15:743-758.

14. Fujita T, Obata K, Kuwahara S, Miura N, Nakahashi A, Monde K, Decatur J, Harada N. (R)-(+)-[VCD (+) 945]-4-Ethyl-4methyloctane, the simplest chiral saturated hydrocarbon with a quaternary stereogenic center. Tetrahedron Lett. 2007;48:42194222.

15. Monde K, Taniguchi T, Miura N, Vairappan CS, Suzuki M. Absolute configurations of brominated sesquiterpenes determined by vibrational circular dichroism. Chirality 2006;18:335-339.

16. Merten C, Smyrniotopoulos V, Tasdemir D. Assignment of absolute configurations of highly flexible linear diterpenes from the brown alga Bifurcaria bifurcata by VCD spectroscopy. Chem. Commun. 2015.

17. Taniguchi T, Manai D, Shibata M, Itabashi $\mathrm{Y}$, Monde K. Stereochemical Analysis of Glycerophospholipids by Vibrational Circular Dichroism. J. Am. Chem. Soc. 2015.

18. Pino P, Lorenzi GP, Chiellini E. Optically active vinyl polymers. $X V$. The optical activity in hydrocarbon solution of poly[(s)-1-methyl propyl]vinyl ether and of poly[(s)-2-methyl butyl] vinyl ether. J. polym. sci., C Polym. symp. 1967;16:3279-3289.

19. Villiers C, Braud C, Vert M, Chiellini E, Marchetti M. Optically active alternating copolymers of maleic acid and alkylvinylethers. Eur. Polym. J. 1978;14:211-217.

20. Angiolini L, Caretti D, Carlini C, Altomare A, Solaro R. Optically active polymers containing side-chain azobenzene moieties: Photochromic and photoresponsive behavior of copolymers of $\mathrm{N}$ (4-azobenzene) maleimide with (-)-menthyl vinyl ether and (+) (S)2-methylbutyl vinyl ether. J. Polym. Sci. A Polym. Chem. 1994;32:2849-2857.

21. Laus M, Bignozzi MC, Fagnani M, Angeloni AS, Galli G, Chiellini $E$, Francescangeli $O$. Liquid Crystalline Poly(vinyl ether)s and Block Copoly(vinyl ether)s by Living Cationic Polymerization. Macromolecules 1996;29:5111-5118.

22. Salvadori $P$, Lardicci L. Relation between rotatory power and optical purity among saturated and unsaturated ethers which are optically active and contain a terminal sec-butyl group. Gazz. Chim. Ital. 1964;94:1205-20.

23. Urbanová M, Setnička V, Volka K. Measurements of concentration dependence and enantiomeric purity of terpene solutions as a test of a new commercial VCD spectrometer. Chirality 2000;12:199-203.

24. Guo C, Shah RD, Dukor RK, Freedman TB, Cao X, Nafie LA. Fourier transform vibrational circular dichroism from 800 to 10,000 $\mathrm{cm}-1$ : Near-IR-VCD spectral standards for terpenes and related molecules. Vib. Spectrosc. 2006;42:254-272.

25. Frisch MJ, Trucks GW, Schlegel HB, Scuseria GE, Robb MA, Cheeseman JR, Scalmani G, Barone V, Mennucci B, Petersson GA, Nakatsuji H, Caricato M, Li X, Hratchian HP, Izmaylov AF, Bloino J, Zheng G, Sonnemberg JL, Hada M, Ehara M, Toyota K, Fukuda R, Hasegawa J, Ishida M, Nakajima T, Honda Y, Kitao O, Nakai H, Vreven T, Montgomery J, J. A., Peralta JE, Ogliaro F, Bearpark M, Heyd JJ, Brothers E, Kudin KN, Staroverov VN, Kobayashi R, Normand J, Raghavachari K, Rendell A, Burant JC, lyengar SS, Tomasi J, Cossi M, Rega N, Millam JM, Klene M, Knox JE, Cross JB, Bakken V, Adamo C, Jaramillo J, Gomperts R, Stratmann RE, Yazyev O, Austin AJ, Cammi R, Pomelli C, Ochterski JW, Martin RL, Morokuma K, Zakrzewski VG, Voth GA, Salvador P, Dannenberg JJ, Dapprich S, Daniels AD, Farkas O, Foresman JB, Ortiz JV, Cioslowski J, Fox DJ. Gaussian 09, Revision D.01. Wallingford CT: Gaussian, Inc.; 2013.

26. Bruhn T, Schaumlöffel A, Hemberger Y, Bringmann G. SpecDis: Quantifying the Comparison of Calculated and Experimental Electronic Circular Dichroism Spectra. Chirality 2013;25:243-249.

27. Owen NL, Sheppard N. Infra-red spectra and structure of methyl vinyl ether. Trans. Faraday Soc. 1964;60:634-645.

28. Freedman TB, Kallmerten J, Lipp ED, Young DA, Nafie LA. Vibrational circular dichroism in the carbon-hydrogen stretching region of $(+)-3(R)$-methylcyclohexanone and chiral deuteriated isotopomers. J. Am. Chem. Soc. 1988;110:689-698. 
29. Abbate S, Castiglioni E, Gangemi F, Gangemi R, Longhi G, Ruzziconi R, Spizzichino S. Harmonic and Anharmonic Features of IR and NIR Absorption and VCD Spectra of Chiral 4-X[2.2]Paracyclophanes. J. Phys. Chem. A 2007;111:7031-7040.

30. Góbi S, Magyarfalvi G. Reliability of computed signs and intensities for vibrational circular dichroism spectra. Phys. Chem. Chem. Phys. 2011;13:16130-16133.

31. Polavarapu PL, Covington CL. Comparison of Experimental and Calculated Chiroptical Spectra for Chiral Molecular Structure Determination. Chirality 2014;26:539-552.

32. Covington CL, Polavarapu PL. Similarity in Dissymmetry Factor Spectra: A Quantitative Measure of Comparison between Experimental and Predicted Vibrational Circular Dichroism. J. Phys. Chem. A 2013;117:3377-3386.

33. Owen NL, Soerensen GO. Microwave spectrum, conformation and barrier to internal rotation of ethyl vinyl ether. J. Phys. Chem. 1979;83:1483-1488.
34. Bloino J, Biczysko M, Barone V. General Perturbative Approach for Spectroscopy, Thermodynamics, and Kinetics: Methodological Background and Benchmark Studies. J. Chem. Theory Comput. 2012;8:1015-1036.

35. Izumi H, Yamagami S, Futamura S, Nafie LA, Dukor RK. Direct observation of odd-even effect for chiral alkyl alcohols in solution using vibrational circular dichroism spectroscopy. J. Am. Chem. Soc. 2004;126:194-198. 


\section{Graphical Abstract}

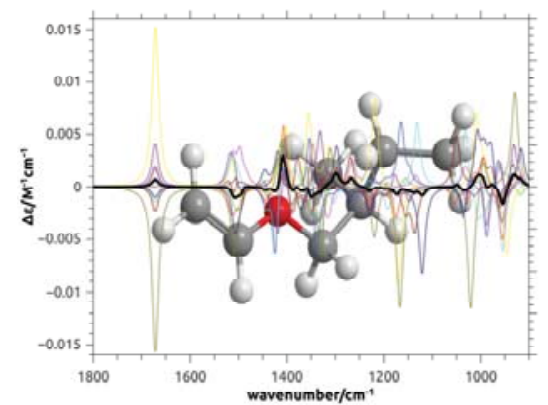

Alkyl vinylethers display zero ECD signal and very weak optical rotations, making vibrational circular dichroism an almost essential tool to solve absolute configuration problems. However, given the many conformational possibilities leading to completely different spectral features, the DFT calculations are not straightforward. Nevertheless, we found that certain bands could be reliably employed as a fingerprint for these and similar compounds. 